\title{
Martin Bajus: Petrochemistry: Petrochemical Processing, Hydrocarbon Technology and Green Engineering
}

\author{
John Wiley and Sons 2020, ISBN 978-1-11964-776-8, pp xxx + 303, Price \$105
}

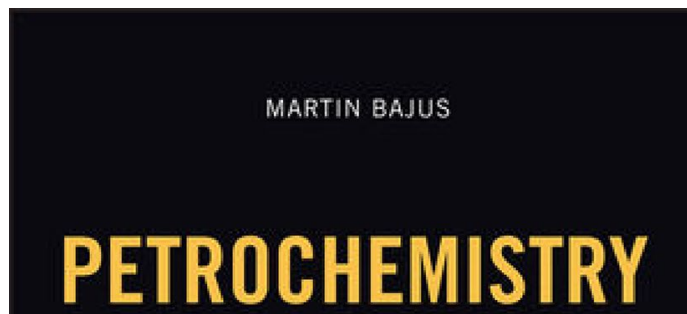

PETROCHEMICAL PROCESSING, HYDROCARBON TECHNOLOGY AND GREEN ENGINEERING

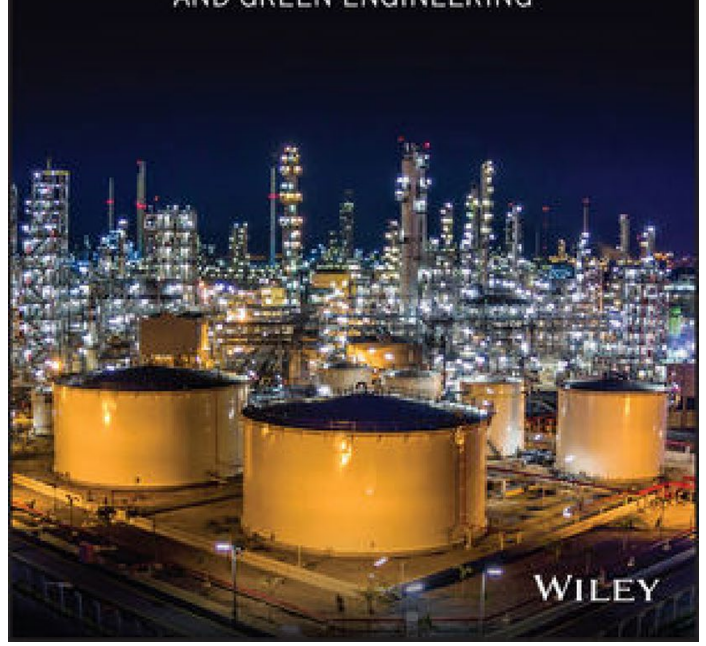

Currently all efforts are directed at reducing carbon emissions, particularly those related to hydrocarbons. One might wonder, therefore, why it is appropriate to have a book on petrochemistry. The answer is that nearly all of the household items of my childhood made of enameled metal or ceramic have been replaced by plastic materials and of course there is also now the non-stick kitchenware coated with PTFT. The modern environmental problem of plastic pollution is surely due to the consumer rather than the manufacturer. The author hails from Slovakia which is not a country one would normally associate with the petroleum industry but it demonstrates the universal importance of the topic.

This book starts with several pages of preface containing first a list of "General Literature", then "Nomenclature" and finally a list of "Acronyms and Abbreviations". These, together with the index at the end of the book give a comprehensive guide to anything one is likely to come across. The author is to be commended for his efforts in this: unfortunately few other authors follow his example. There are numerous illustrations in black and white and color. At the end of Chapter 1 (on pages 41-2) there is a list of the major chemical companies worldwide, Shell and BP are not listed for the simple reason that they have withdrawn from producing petrochemicals as opposed to fuels and ICI (once the largest UK chemical company) has virtually ceased to exist.

The first five chapters introduce various topics which are enlarged in those that follow. Chapter 6 (alkenes) onwards follow a natural sequence of compound types progressing to aromatics (Chapter 10) and then on to a mixture of topics such as greenhouse gas (Chapter 12) to hydrogen technologies (Chapter 13) to miscellaneous techniques in the remaining chapters.

This is a major contribution to the literature with a comprehensive covering of the subject with unlikely topics such as coke formation which is discussed in Chapter 7. This book must be considered essential reading for all new graduates in this field.

E. R. Adlard.

Publisher's Note Springer Nature remains neutral with regard to jurisdictional claims in published maps and institutional affiliations. 